\title{
THE CHAIN BREAKAGE PROBLEM AT THE SÃo PAUlO PELlETRON ACCELERATOR FACILITY
}

\author{
T. POLGA and O. SALA \\ University of São Paulo, São Paulo, Brasil
}

\begin{abstract}
Résumé. - Les problèmes des ruptures de chaîne ainsi que les moyens de surmonter ces difficultés dans le cas du Pelletron 8UD à São Paulo sont décrits.

Abstract. - The chain breakage problem and the way to overcome this difficulties in the case of the 8UD Pelletron in São Paulo are described.
\end{abstract}

Our 8UD Pelletron accelerator became operational on june 1972 [1] and until the end of 1975 it has been plagued by frequent breakages of the pellet chains. Several unsuccessful attempts were made during that time in order to solve the problem [2]. Several different mounting for the guide pulleys (idlers) were tryed. The see-saw stretching systems for the chains were changed to a linear bearing sliding systems [2]. Different mountings for the drive pulleys oiling system were tryed [2]. The best record with no breakage was 2800 hours for one $11 / 8^{\prime \prime}$ chain, over the first 8000 hours of operation completed at the end of 1975 . At the same time a nylon test body placed inside the accelerator tank during operation had been showing evidence of changes in the mechanical properties. This was understood as being caused by a chemical attack by $\mathrm{SF}_{6}$ breakdown products produced by accelerator sparks and, mainly, by the corona discharge along the column voltage dividing bleeder, which is unclosed in our machine. On the assumption that the chains problem was caused by this chemical attack on the nylon links, in jannuary 1976 we installed a new gas recirculating system, with twice the gas flow ( $~ 50 \mathrm{l} / \mathrm{s}$ at atmospheric pressure) than the one originally supplied by NEC [3]. At the same time all the guide pulleys were removed, the nylon of the drive pulleys rims was replaced by poliethilene HMW-1900, the remotely actuated oiling system was completely removed and we started to lubricate locally the chains and the rims every 700 hours, on the average [3], using Duo - Seal pump oil. A new nylon test body has shown that allumina is adequate to remove $\mathrm{SF}_{6}$ breakdown products when properly used. The gas flow of our present recirculation system is sufficient to recirculate all the volume of the accelerator tank twice every hour at atmospheric pressure. The fitter takes approximatly 301 of allumina pellets and the reactivation is perfomed every 400 hours of operation keeping the allumina at a temperature between 120 and $150^{\circ} \mathrm{C}$ during 30 minutes with dry air flowing the filter. Up to this date we have got no more chains break, after running in excess of 5000 hours.

\section{References}

[1] SAla O. and Spalek G., Nucl. Instrum. Methods 122 (1974) 213.

[2] Polga T. and Sala O., Low Energy Nuclear Physics Annual Report-Nuclear Physics Department, University of São Paulo (1975) 103.

[3] Idem (1976). In press. 